\title{
Simulation Study of Breakup and Atomization Characteristics of Gasoline- Ethanol (GASHOLS) Fuel Blends
}

\author{
I. Altraide ${ }^{1}$, P.N. Josiah ${ }^{2}$, O.M.O. Etebu ${ }^{3}$, J.G. Akpa ${ }^{4}$ \\ ${ }^{1}$ World Bank Africa Centre for Excellence in Oilfield Chemicals Research, University of Port Harcourt, Choba, Nigeria \\ ${ }^{2}$ World Bank Africa Centre for Excellence in Oilfield Chemicals Research, University of Port Harcourt, Choba, Nigeria \\ ${ }^{3}$ Department of Mechanical Engineering, University of Port Harcourt, Choba, Nigeria \\ ${ }^{4}$ Department of Chemical Engineering, Rivers State University, Nkpolu-Oroworukwo, Rivers State, Nigeria
}

\begin{abstract}
To meet the increasingly stringent constraints on mobile and point emissions in the wake of the dwindling fortunes of fossil fuels, evaluation of hybrid fuels for application in combustion engines has become an imperative, especially in the third world countries. This paper presents, modeling of atomization characteristics of gasoline-ethanol fuel blends. Fuel breakup models and correlations between flow patterns and droplet characteristics were adopted and implemented in OpenFOAM Computational Fluid Dynamics (CFD) modeling suite for direct gasoline injector using a simple cylindrical mesh structure at constant volume. The Rosin Rammler distribution model was used to generate the number of spray particles injected into the cylinder. The spray modeling and atomization employed the use of blob sheet model and Kelvin-Helmholtz-Rayleigh-Taylor (KH-RT) model while the numerical technique for simulating atomization process by CFD included the use of governing equations such as Eulerian for gas phase, Lagrangian for disperse phase and turbulence modeling. The effects of fuel blends, injection pressure, ambient gas pressure and spray cone angle were evaluated on the axial spray tip penetration, spray width, and overall Sauter Mean Diameter (SMD). The SMD was seen to be affected by varying the degree of injection cone angle. The spray tip penetration lengths were larger for higher injection cone angles while higher penetration lengths were obtained at higher injection pressures. One salient conclusion drawn from the modeling is that as the number of particle increased, the density of clusters became smaller.
\end{abstract}

KEYWORDS: SMD, Cone angle, gasohol, fuel-bled, atomization, spray.

\section{INTRODUCTION}

Atomization is a phenomenon that entails the repeated breakup of bulk liquid into an ensemble of droplets, (sprays) with the attendant effect of increasing the volume to surface area ratio. To initiate atomization, external energy is required to overcome surface tension and such energy could be obtained through aerodynamics, mechanically, ultrasound or electrostatics. Atomizers are used for effecting atomization and several variants, including the air-assisted and pressure atomizers are employed in various fields such as agricultural irrigation pesticides application, fluid catalytic cracking, spray drying waste fuel reuse and medical applications. However, in spite of its importance, exact mechanisms and process paths for primary breakup in some application areas such as high speed sprays are poorly understood and remain unresolved. The need for better understanding of primary breakup on one hand and atomization on the other provides the impetus for the myriad of research efforts in both computational and experimental studies on breakup and atomization of diesel and associated liquid fuels.

In the wake of the dwindling fortunes of non-renewable sources of energy and the growing interests in the reduction of greenhouse gases and other deleterious emissions emphasis is shifting to the utilization of regenerative fuels. Gasoline-ethanol blends as fuels as an alternative strategy for replacing hydrocarbon fuels, have received considerable attention in developed economies of the world. Moreover, growing concerns about pollutants emissions from fossil fuel engines and that of rapid depletions of the world's crude oil reserves have necessitated alternative fuel sourcing. Studies on spray properties of various blends at ambient conditions, vapour pressure measurements and spatial analysis have been conducted.

However, relative to studies on diesel and bio-ethanol, much less attention has been given to atomization and spray modeling of gasoline-ethanol fuel blends. Gasoline is a mixture of hydrocarbons and does not exist in pure form. It is synonymous with motor spirit, motor fuel and petrol. Here, gasoline fuel is considered as G100 (Heptane) with molecular formula, $\left.\mathrm{C}_{7} \mathrm{H}_{16}\right)$. Ethanol $\left(\mathrm{C}_{2} \mathrm{H}_{6} \mathrm{O}\right)$, also known as ethyl alcohol can be produced from sugarcane, corn, wood, beet, potato, cassava, wheat and agricultural waste through fermentation while Gasoline-Ethanol blends are referred to as GASHOLS. 
Regarding previous related work, Ejim et al [1] analyzed seven biodiesels as well as their binary and ternary blends at a constant temperature. The Sauter Mean Diameter (SMD) of droplet was reported but no attempt was made regarding correlation of injector geometry, fluid properties and atomization characteristics. In Lebas et al [2] the atomization characteristics of sprays in the dense zone was studied using Direct Numerical Simulation (DNS) and the Eulerian-Lagrangian Spray Atomization (ELSA) models. This contribution is purely a simulation study in which experimental data drawn from previous work was used for parameter estimation. Gao et al. [3] studied the atomization and spray characteristics of gasoline, ethanol and various blends of gasoline and ethanol. In particular blends consists of $75 \%$ gasoline and $25 \%$ ethanol (E25), 50-50\% blend of gasoline and Ethanol (E50), 25\% gasoline and 75\% ethanol (E75) were studied under various ambient conditions, by means of high-speed Schlieren photography. Results from the study show that at high pressures, spray development patterns are not significantly different for the various blends and the zero blends. However, spray trip penetration decreases and spray angle increases with increases in ethanol fraction in the blended fuel, at low pressure. Although, the images clearly affirm the authors' position, the authors were silent on the basis for volume of ethanol in the blends that were studied.

In Aleifens et al [4] a study on the study development of gasoline, iso-octane and ethanol in a spark-ignition engine was presented. According to the authors, the spray characteristics of fuels differ between hot and cold engine operation to a large extent. Regarding spray development, slight differences were noticed among all fuels at an engine head temperature of $20^{\circ} \mathrm{c}$. However, spray cone angle was found to have reduced considerably at an engine head temperature of $80^{\circ} \mathrm{c}$. Reitz [5] presented a theoretical basis and numerical implementation of KIVA, which is a multidimensional computer code for the simulation of atomization and vapourization processes in the injection of a liquid through a round hole. The author presented the prediction of KIVA for different regimes and compared same with published experimental data, and demonstrated good agreement with published data. Although, boundary element and finite volume methods are well suited for, structural analysis and free surface flows.

In Hassainpour and Ninesh [6] computational fluid dynamics (CFD) code was adopted in a study of sprays in direct injection engines. The discrete droplet method, a statistical tool was employed for spray calculations by the authors. Based on experimental validation, the authors reported that spray penetration and emission characteristics are predicted better with modeling methodologies. Other authors such as Jiang et al. [7] explained the use of CFD in complex processes. A study of droplet-gas system configured in a three-dimensional model which accounted for atomization of parent droplets was reported in Lijuan et al. [8] Deduction from this study, point to the air-to-liquid ratio in the effervescent atomizer as having strong influence on droplet size and distribution. Soybean oil methyl ester (SME) atomization was reported by Park et al. [9].Their results showed similar SMD distribution patterns for biodiesel and diesel in comparison with experimental droplet size distribution. Park et al. [10] studied conditions for atomization of soybean oil Methyl ester (SME) fuel, nozzle tip and SMD were calculated. SME physical properties were used as input in KIVA code.

Kim et al [11] analyzed atomization performances of three fuels. Tip penetration of spray, width spray cone angle and SMD were determined by experiment and predicted by KIVA-3V code. Deductions from their study point to droplet size as being proportional to fuel physical properties. Microscopic droplets behavior of diesel and biodiesel was studied by Htung et al. [12] The KIVA-3V code, the Taylor Analogy Breakup (TAB) model and its modifications were used as numerical tools for quantifying experimental results. Other notable experimental studies are those of Shinjo and Umemura [13], Zhoulang et al [14], Lee and Park [15], Cipolat and Valentim [16]. Theoretical and experimental injection spray characteristics were compared in a study by Zhao et al. [18]. Two models that were drawn from the literature were compared on the basis of capacity to duplicate experimental data. A high speed camera was used to observe the deformation and breakup behavior of coal water slurry cylindrical jet surrounded by an annular airflow.

Four types of breakup namely Rayleigh breakup, membrane breakup, fiber breakup and atomization were studied based on dimensionless numbers and experimental data. The authors drew several conclusions, one of which is that jet breakup length decreases with increase in Weber number and increases with increasing Ohnesorge number. Several other studies on breakup models relied heavily on either existing open source KIVA-3V code or other models. Moreover, most of them are local to diesel fuel sprays and biodiesel. Among this category are the contribution in Kawahara et al [18], Jiang et al [19], Vita and Alloca [20] . $\mathrm{Su}$ et al [21] studied the atomization and breakup characteristics of liquid jets at various spray conditions, using the large eddy simulation approach. A combined Eulerian-Lagrangian approach was adopted to describe the spray field dynamics. The liquid column and the droplet breakup processes were simulated using a Kelvin-Helmboltz and Rayleigh-Taylor (KH-RT) hybrid wave breakup model. Reasonable agreement between model predictions and experimental data was demonstrated by the authors. However, TVD Range-Kutta method was used to solve the modeling equation without recourse to CFD codes.

Experimental procedures for studying fuel breakup characteristics are well documented in the open literature. However, the focus has been on diesel, biodiesel and bioethanol, while little attention has been given to gasoline- 
ethanol blends. Moreover, there is paucity of data of spray characteristics of diesel fuels in the dense region (near field) while such experimental data is non-existent for gasolineethanol fuel blends beyond (E10). Regarding modeling efforts, the existing breakup and spray models center around Kelvin-Helmholtz (k-H), Rayleigh-Taylor (RT) instability, Raynolds -Averaged - Navier-Stokes, Taylor-Analog breakup, wave breakup and modified forms. Such modifications where they are introduced are local to the fuel and the atomizer that is studied. Hence, the results from such modeling efforts can hardly be adopted for gasolineethanol fuel blends. More so, some of the simplifying assumptions such as droplets maintaining uniform temperature throughout a spray plume needs to be addressed.

In internal combustion engines, atomization, transport and evaporation are necessary precursors to combustion. However, no models exist that capture each of the phenomena as they relate to gasoline-ethanol fuel blends. Although the predictive accuracy of existing breakup models have been tested on diesel and other fuels, such tests on gasoline-ethanol fuel blends are either not documented or poorly attended to. Regarding, the use of spray distribution functions, no consensus has been reached on the most reliable one; the purpose of this paper is to apply models to the study of breakup and atomization characteristics of blends of gasoline and ethanol fuels, using Openfoam and MatLab as computational and spray visualization platforms.

\section{MODELING OF BREAKUP AND ATOMIZATION}

\section{1: Blob Sheet Model}

The blob sheet model is presented in fig 1 and the breakup rate is given as:

$$
\frac{d D_{p}}{d t}=k_{l} \frac{L_{A}}{\tau_{A}}
$$

The proportionality constant $k_{l}$ is subject to calibration, $L_{A}$ is the dominant length scale of atomization.

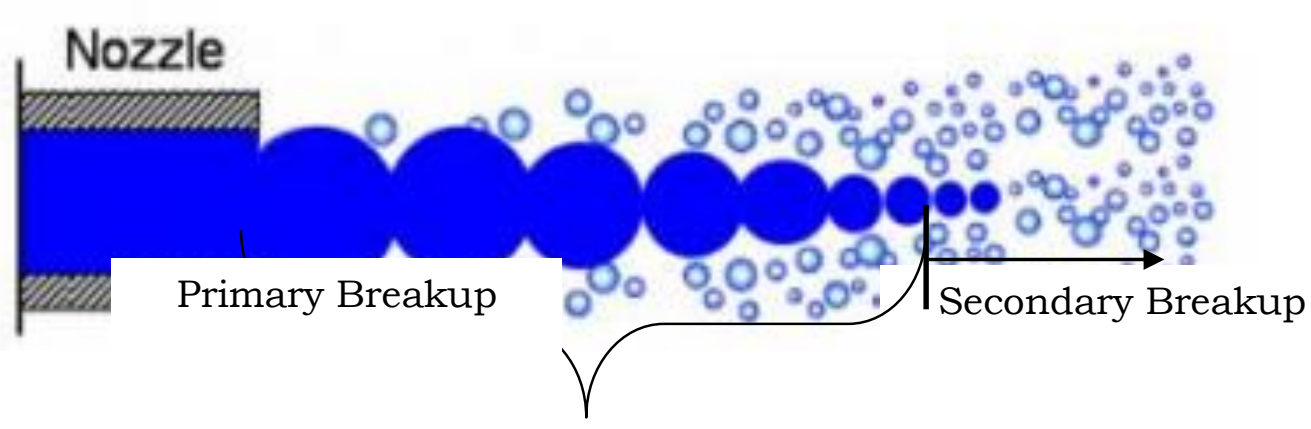

Figure 1: A typical representation of the blob-injection model

The model assumptions are:

- The length $\mathrm{L}_{\mathrm{A}}$ :

$$
L_{A}=C_{1} \times L_{t}=C_{2} \times L_{w}
$$

The atomization scale is the linear sum of the turbulence and wave growth time scales:

Turbulence quantity dissipation rate is given as:

$$
\begin{gathered}
L_{t}^{0}=C_{\mu} \frac{k_{a v g}^{3 / 2}}{\varepsilon_{a v g}} \\
\tau_{t}^{0}=C_{\mu} \frac{k_{a v g}}{\varepsilon_{a v g}} \\
\mathrm{C}_{\mu}=0.09 \text { and the average quantities are estimated }
\end{gathered}
$$

as:

$$
k_{a v g}=\frac{u^{2}}{8(L / D)}\left[\frac{1}{c_{d}^{2}}-k_{c}-\left(1-s^{2}\right)\right]
$$

$$
\boldsymbol{\varepsilon}_{a v g}=k_{\varepsilon} \frac{\boldsymbol{u}^{2}}{2 L}\left[\frac{1}{c_{d}^{2}}-k_{c}-\left(1-s^{2}\right)\right]
$$

Turbulence length

$$
L_{t}(t)=L_{t}^{0}\left(1+\frac{0.0828 t}{\tau_{t}^{0}}\right)^{0.457}
$$

Time scale

$$
\tau_{t}(t)=\tau_{t}^{0}+0.0828 t
$$

Wave growth time scale $\tau_{w}=\frac{L_{w}}{U} \sqrt{\frac{\rho_{L}}{\rho_{g}}}$

\section{2: Wave Model}

The wave model (KH model) is where the stability analysis of round liquid jets is developed. The droplet breakup (Kelvin-Helmholtz instability) of liquid jet has initial radius $r$ and $\eta_{0}$ is an infinitesimal initial perturbation as shown in Fig 2. 
Radius change of this droplet is calculated as:

$$
\frac{d r}{d t}=\frac{r-r_{n e w}}{\tau_{b u}}
$$

Where, $\tau_{b u}$ is the characteristic breakup time scale defined by:

$$
\tau_{b u}=3.788 B_{1} \frac{r}{\Lambda \Omega}
$$

And the new droplet radius given as;

$$
r_{\text {new }}=B_{0} \Lambda
$$

Where $B_{0}$ and $B_{1}$ are constants

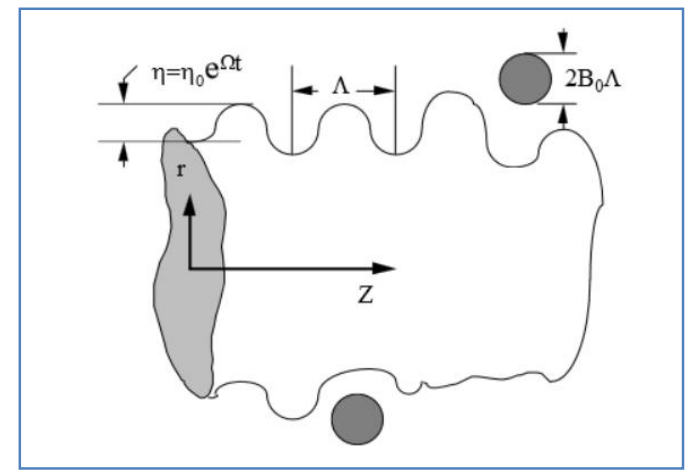

Figure 2: Kelvin-Helmholtz model

$$
B_{0} \Lambda \leq r
$$

Maximum growth rate

$\Omega=\frac{0.34+0.38 W e_{g}{ }^{15}}{(1+z)\left(1+1.4 T^{0.6}\right)}\left[\frac{\sigma}{\rho_{l} r^{3}}\right]^{0.5}$

Wavelength

$\Lambda=9.02 r \frac{\left(1+0.45 Z^{0.5}\right)\left(1+0.4 T^{0.7}\right)}{\left(1+0.865 W e_{g}{ }^{1.67}\right)^{0.6}}$

Where, $\quad Z=\frac{\sqrt{W e_{l}}}{\operatorname{Re}_{l}}=\frac{\mu_{l}}{\sqrt{\rho_{l} r \sigma}}$ Ohnesorge number, $T=Z \sqrt{W e_{g}}$ Taylor number, and $W e_{g}=\frac{\rho_{g} r u_{r e l}^{2}}{\sigma}$ and $W e_{l}=\frac{\rho_{l} r u_{r e l}^{2}}{\sigma}$ are gas and liquid Weber numbers, respectively and $u_{r e l}$ velocity of liquid droplet relation to stationary gas phase (Beale and Reitz, 1999).

\subsection{KH-RT Model}

This model consists of two modes of breakup: The KelvinHelmholtz $(\mathrm{KH})$ breakup which accounts for instability in the waves growing and Rayleigh-Taylor (RT) breakup.
Rayleigh-Taylor (RT) breakup is governed by the rapidly growing disturbances on the surface of the droplet. Wave, $\Omega_{R T}$ wavelength, $\Lambda_{R T}$ were given in equation (16) and (17), respectively:

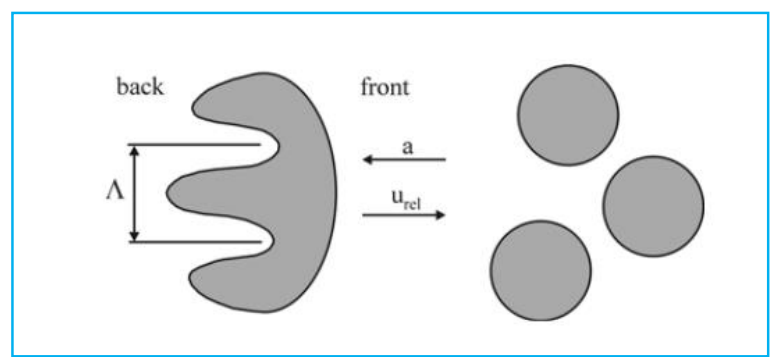

Figure 3: Rayleigh -Taylor (RT) instability.

$$
\begin{array}{r}
\Omega_{R T}=\sqrt{\frac{2\left[a_{d}\left(\rho_{l}-\rho_{g}\right)\right]^{1.5}}{3 \sqrt{3 \sigma}\left(\rho_{l}+\rho_{g}\right)}} \\
\Lambda_{R T}=2 \pi C_{R T} \sqrt{\frac{3 \sigma}{a_{d}\left(\rho_{l}-\rho_{g}\right)}} \\
a_{d}=\frac{3}{8} C_{d}\left(\frac{\rho_{g} u_{r e l}^{2}}{\rho_{l} r}\right)
\end{array}
$$

Where, $a_{d}$ is the droplet acceleration, $C_{d}$ is the injector nozzle's discharge coefficient and $C_{R T}$ is the modeling parameter.

The breakup time scale is expressed as:

$$
\tau_{R T}=\frac{C_{1}}{\Omega_{R T}}
$$

Where, $C_{1}$ is the modeling constant, when the growth time exceeds the characteristic Rayleigh-Taylor (RT) time, breakup occurs and the droplet is converted into parcels of smaller droplets. The new droplets formed are taken to be of uniform diameter.

\section{COMPUTATIONAL FRAMEWORK}

The spray injected into a constant volume cylinder is simulated using the Eulerian-Lagrangian approach. Small computational cells composing Meshes (8900) with fluid density, velocity, pressure and enthalpy were computed and stored on each computation cell. Gas (continuous) is simulated using the Eulerian formulation in ReynoldsAveraged Navier-Stokes (RANS) equation alongside Realizable k-e turbulence model which accounts for effect of turbulence fluctuations in the fluid phase. Similarly, the liquid (discrete or disperse) phase is treated using a Lagrangian formulation together with spray sub-models.

The density, surface tension and viscosity of gasoline and ethanol fuels were computed internally and imported as 
input data. The inlet and exit temperatures and pressures were defined. A cylindrical system with consideration of all boundaries as walls and mesh coordinates were set to be symmetrical with an assumption of no heat loss. The mesh generation was taken to be one-quarter of a cylinder which was simulated by defining the process to be a transient compressible system where there were variations of pressure. The reason for assuming symmetry in the cylinder is the use of cone injector model, hence it is considered a hollow injector atomizer so it can be symmetrical at $45^{\circ} \mathrm{C}$ per cross section.

The inner nozzle diameter which was obtained from standard nozzle design is taken to be $100 \mu \mathrm{m}$. The study spray characteristics of gasoline fuel $\left((\mathrm{G} 100)-\mathrm{C}_{7} \mathrm{H}_{16}\right)$ was done by simulation using OpenFOAM source code which runs on Linux platform. This analysis was affected using SimFlow to generate meshes for the simulation and run. The mesh and results files were saved to the OpenFOAM file format and visualized in ParaView software. Further analysis was done with MatLab by saving in the MatLab directory. In the simulation, only a quarter of cylinder was used in the simulation. Two of the boundaries were set to symmetry and the remaining boundary set to wall.

The sprayfoam solver is the solver type that was used to simulate a transient, compressible, reacting and noncombustible fuel injection process. High pressured fuel at $5 \mathrm{MPa}$ at $300^{\circ} \mathrm{K}$ was injected into high temperature $\left(800^{\circ} \mathrm{K}\right)$ stagnant air at a velocity of $100 \mathrm{~m} / \mathrm{s}$. The Turbulence Model of RANS - Realizable k-e model, with heat transfer model of Ranz-Marshall as well as phase change model which is liquid evaporation-boil model was adopted in boundary interaction (rebound) in secondary atomization.

\section{RESULTS AND DISCUSSION \\ 4.1: Effects of Fuel - Blend Composition on Sauter Mean Diameter}

Fig 4 and 5 each show the SMDs of different proportions of GASHOL at different injection cone angles. There are four regimes in the plot that are described using the y-intercepts as starting points The particle diameter experiences exponential decay until a point of stability is reached at $40 \mu \mathrm{m}$ then there is no further drop taking place. The optimal particle diameter for $\mathrm{G} 100$ is $30 \mu \mathrm{m}$, which is the reference point of the pure gasoline. In the middle regime pure gasoline is the most stable while the blends are relatively unstable and therefore atomize continuously more. E85 at $200 \mu$ s present as best atomizing blend. Also between $200 \mu \mathrm{s}$ and $1000 \mu \mathrm{s}$ the best atomizing blends are in the order of $\mathrm{E} 85, \mathrm{E} 15, \mathrm{E} 50, \mathrm{G} 100$ and E100. At $1250 \mu \mathrm{s}$ is a point of convergence where all the blends atomize at the same rate. Beyond $1250 \mu$ s time after start of energizing E100, E15, E50, E85 and G100 show in that sequence.

The plot also showed that major atomization of the blends concludes at $1250 \mu \mathrm{s}$. The closest SMD to that of pure ethanol is E15 after which is E50 then E85 at $1250 \mu$ s to $5000 \mu \mathrm{s}$. The implication and interpretation in the exhibited patterns of Gashol is that E15 would be the best blend or the best product mix in terms of atomization. The main difference between figures 4 and 5 is the display of the effect of change in injection cone angle. Fig 5 shows that SMDs, atomization continues more steadily and intensely than at injection cone angle of 30 degrees. The prediction of the overall SMD is important in that it tells the overall average diameters of the droplets of the mixture after atomization hence, figure 4 describes the overall SMDs.

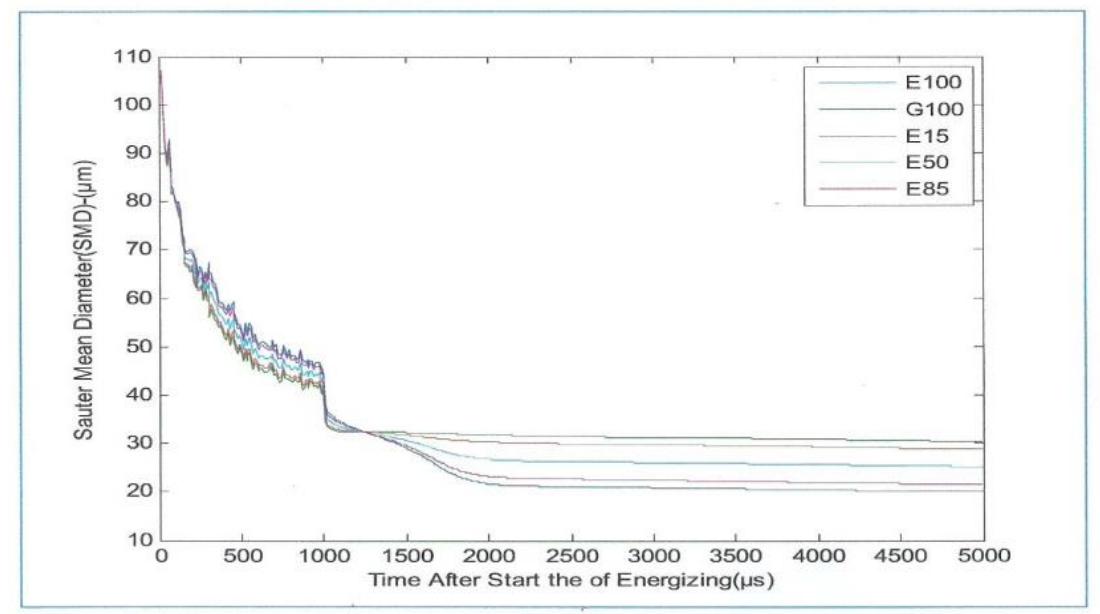

Figure 4: Sauter Mean Diameter (SMD) for different blends of fuel at cone injection angle of 30 degrees 


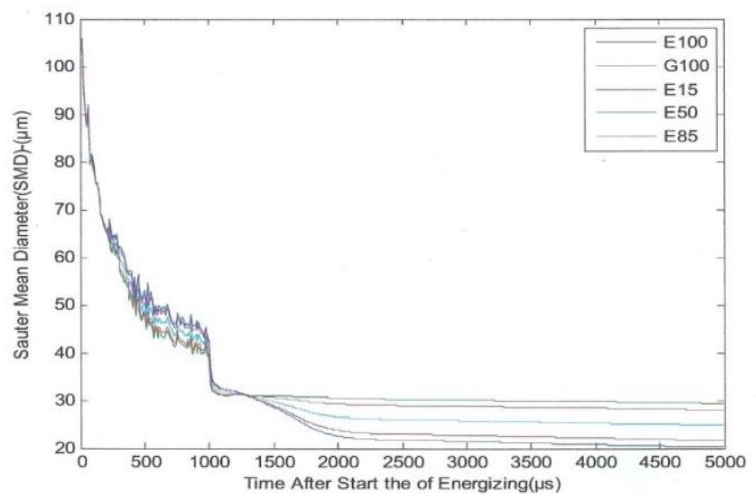

Figure 5: Sauter Mean Diameter (SMD) for different blends of fuel at cone injection angle of 40 degrees

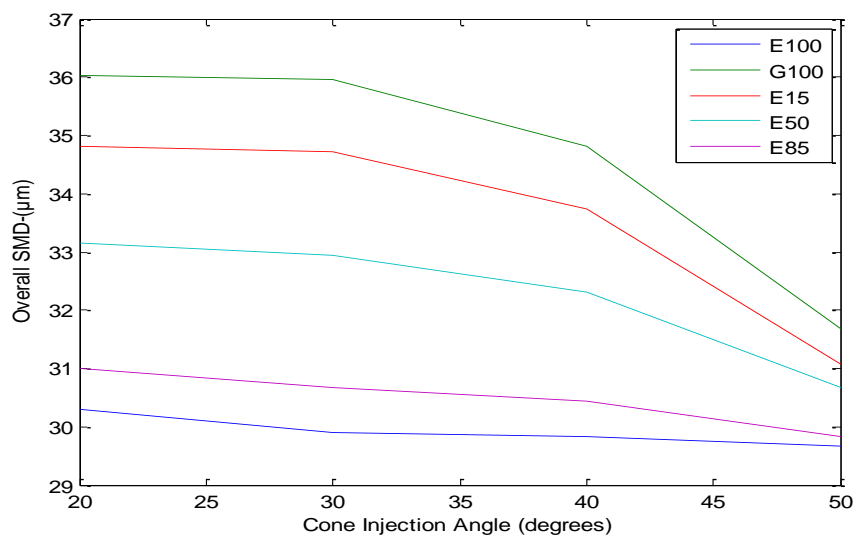

Figure 6: Overall Sauter Diameter (SMD) for Gashol at different cone injection angles.

Fig 6 describes the behaviour of cone injection angle in relation to overall SMDs of E100, G100, E15, E50 and E85. In other to determine overall SMDs, one droplet per micro second for every injection cone angle was adopted. Overall SMD was obtained by taking the average of all the droplets in the cylinder at each injection and so for each injection obtains one point value. This culminates to the total droplet sizes known as overall SMD. Where the overall SMD is decreasing with increase in cone injection angle, the interpretation is better occurrence of atomization.

The properties of mixture of Gashol are important to determining the spray tip penetration. The pressure, density and viscosity were obtained from secondary sources for the analyses of spray tip determination.

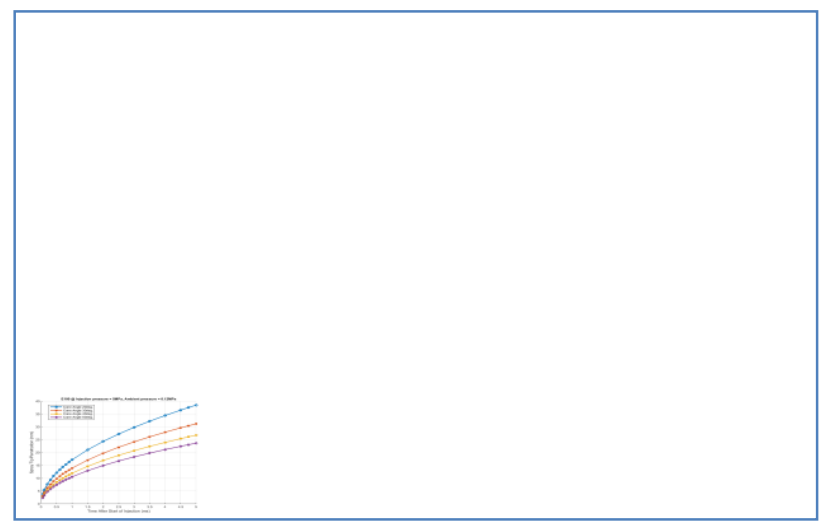

\section{2: Spray tip penetration}

The spray tip penetration can be said to be the maximum distance considered within the spray axis to which the spray can advance from the nozzle tip [22] and [23]. It is one of the macroscopic characteristics that have been studied especially in diesel fuel application. Fig 7 shows the relationship between GASHOL composition and spray tip penetration. The profiles reveal that spray tip penetration characteristics of the injected fuel is not affected by the difference in the fuel composition of E100, E15, E50, E85 and G100 fuels. However, the magnitude of occurrences is significant in the light of the trajectories in fig 8 .

Figure 7: Effect of Gashol properties on spray tip penetration at different times after start of injection 

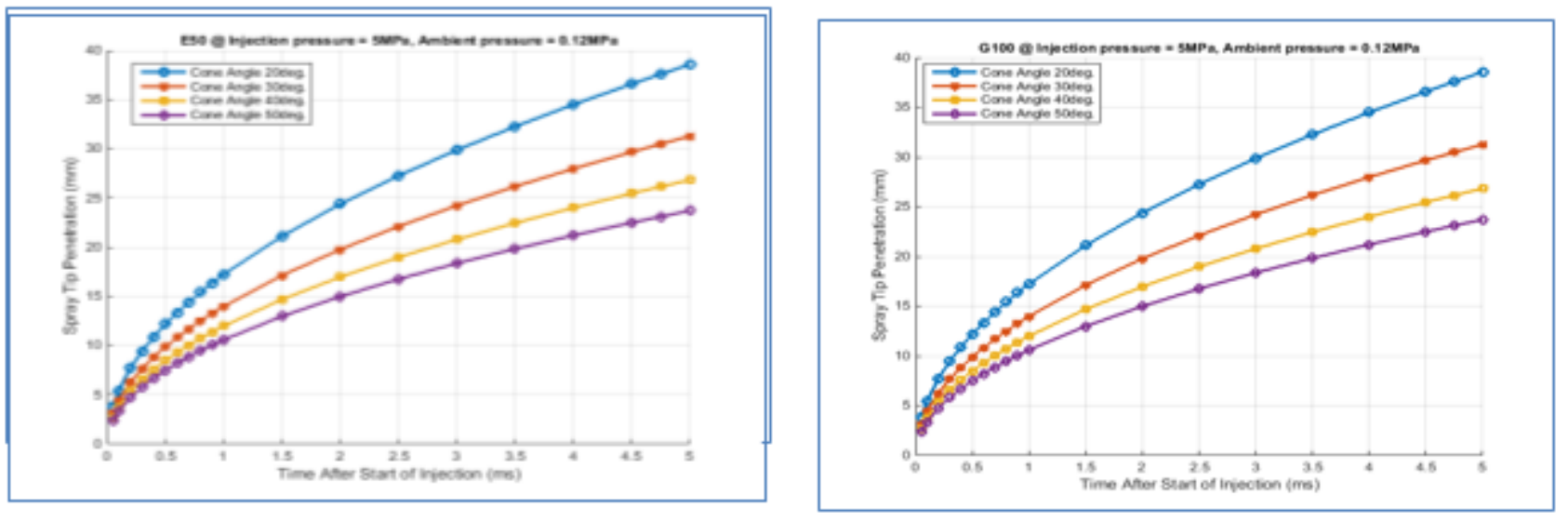

Figure 8: Effects spray cone angle on the spray penetration length.

These results indicate that larger penetration lengths are obtained with higher injection angles. The influence of the cone angle is highly significant compared to that of the injection pressure. Figure 9 describes the effects of fuel injection pressure on the spray penetration. The increase of the injection pressure induced an increase of the relative velocity between the injected spray and ambient gas. Thus, higher penetration lengths are obtained at higher injection pressures.
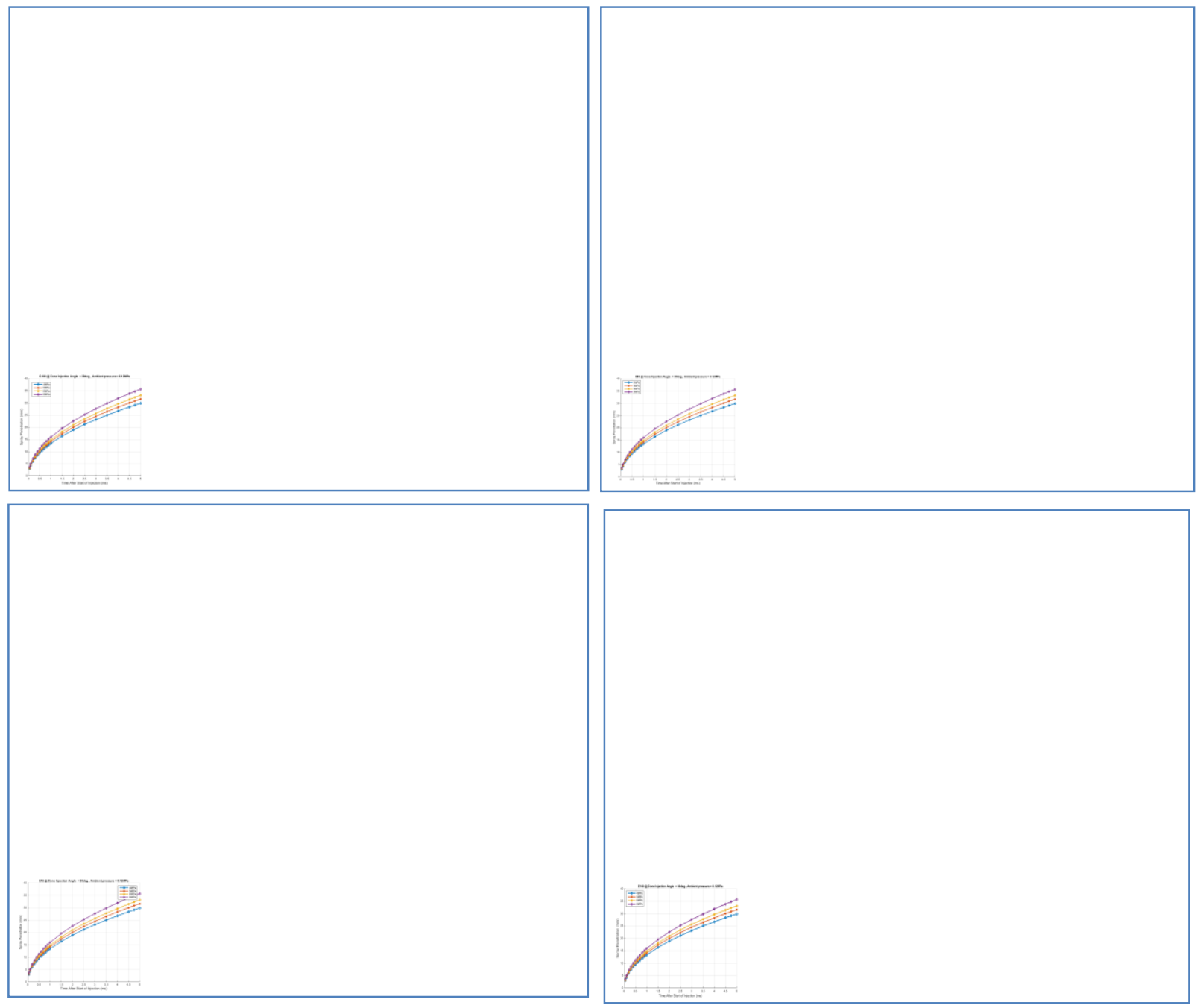


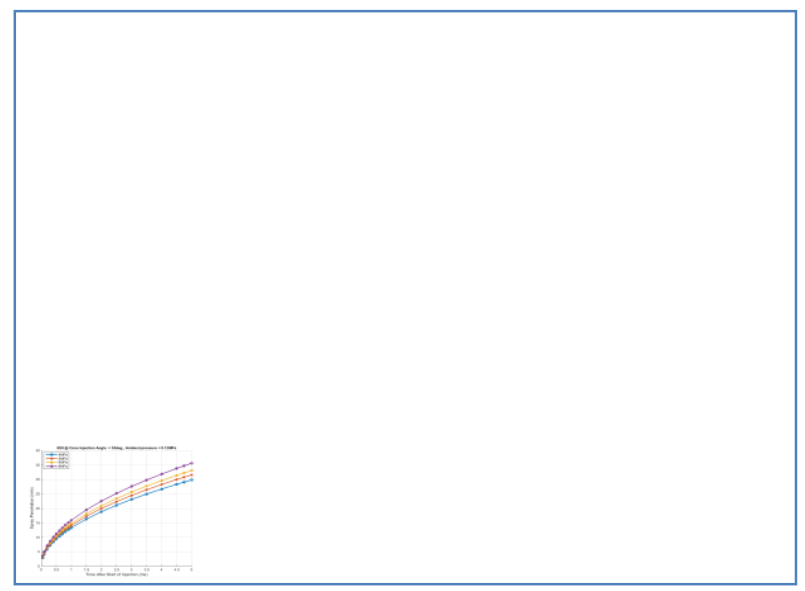

Figure 9: Effect Injection Pressure on Spray Tip Penetration at different times after start of injection.

\section{5: Conclusion}

A simulation study that employs Blob model and KH-RT models has been presented in this paper. A very important inference from this paper is that in the absence of precision cameras, software tools can easily be employed for imaging and flow visualization.

\section{REFERENCES}

1. C.E. Ejim, B.A. Fleck and A. Amirfazli,"Analytical study for atomization of biodiesels and their blends in LI typical injector: Surface tension and viscosity effects". Fuels, 86, 1 534-1 544, 2007.

2. R. Lebas, T. Menard; P.A. Beau; A. Berlement; E.X. Demoulin,"Numerical Simulation of primary breakup and atomization: DNS and modeling study". International Journal of Multiphase Flow, 35, 247-260, 2009.

3. J.Goa, D.Jiang and Z.Huang,"Spray properties of alternative fuels, a comparative analysis of ethanolgasoline blends and gasoline, Fuel 86, pp. 16451650, 2007.

4. P. G.Aleiferis, J. S.Malcolm, A. R.Todd, A.Cairns and H.Hoffmann,"Anoptical study of spray development and combustion of ethanol, iso-octane and gasoline in a DISI engine", SAE Paper, 010073, 2008.

5. R. D.Reitz, "Modeling Atomization Processes in High-Pressure Vaporizing Sprays"Atomization and Spray Technology Journal, Vol. 3, pp. 309-337, 1987.

6. S.Hossainpour and A.R. Binesh,"Investigation of fuel spray atomization in a DI heavy-duty diesel engine 'and comparison of various spray breakup models". Fuel, 88, 795-805, 2009.

7. X.Jiang, G. A.Siamas, K.Jagus and T. G.Karayiannis, "Physical modelling and advanced simulations of gas-liquid two-phase jet flows in atomization and sprays",Progress in Energy and Combustion Science,Vol. 36 pp. 131-167, 2010.
8. O. Lijuan, J. Lin and H. Xiong, "Simulation of droplet-gas flow, in the effervescentatomization spray with an impinging plate". Fluid flow and transport phenomena, 17(1), 8-19, 2009.

9. S.H.Park, J. K. Hyung; K. S. Hyun; S.L. Chang “A study on the fuel injection and atomization characteristics of Soybean Oil Methyl Ester (SME)"International journal of heat and fluid flow, 30, 108-116, 2009.

10. S.H. Park, J. K. Hyung, K. S. Hyun; S. L. Chang."Experimental and numerical of sprayatomization characteristics of biodiesel fuel in various fuel and ambient temperature conditions.International".Journal of Heat and Fluid Flow, 30, 960-970, 2009b.

11. S. Kim, J. W.Hwang and C.S. Lee,"Experiments and modeling on droplet motion and atomization of diesel and bio-diesel fuels in a cross-flowed air stream". International Journal of Heat and Fluid Flow, 31,667-679, 2010.

12. Huang Jun Kim, Su Han Park, Chang Sik Lee, "A study on the macroscopic spray behaviour and atomization characteristics of biodiesel and dimethyl ether sprays under increased ambient pressure". Fuel Processing Technology, 91, 354363, 2010.

13. J.Shinjo, and A. Umemura, "Surface instability and primary atomization characteristics of straight liquid jet sprays"International Journal of Multiphase Flow, 37, 1294-1304, 2011.

14. L. Zhouhang, W. Yuxin, C. Chungrong, Z. Hai, G.Yingli and KeijiT."Mixing and atomizationcharacteristics in an internal mixing twin-fluid atomizer".Fuel, 97, 306-314, 2012.

15. S. Lee and S. Park. "Experimental study on spray break-up and atomization processes from GDI injector using high injection pressure up to $30 \mathrm{MPa}$ ". International Journal of float and Fluid Flow 45, 14-72, 2014. 
16. D. Cipolat, and D.Valentim, "Comparison of theoretical and experimental diesel and DMe injection spray characteristics”, 107, 36-43, 2013.

17. Z.H.Li, B.Q. He and H. Zhao,"Application of a hybrid breakup model for the spray simulation of a multi-hole injector used for a DISI gasoline engine". Applied Thermal Engineering 65, 282292, 2014.

18. N.Kawahara, E.Tomita, D. Kasahara, T. Nakayama and M. Sumida,"Fuel breakup near nozzle exit of high-pressure swirl injector for gasoline direct injection engine", SAE Technical Paper 2004-01-0542, 2004.

19. De-Jun Jiang, Hai-Feng Liu, Wei-Feng Li, JianLiang $\mathrm{Xu}$, Fu-Chen Wang, XinGong,"Modeling atomization of a round water jet by a high-speed annular air jet based on the self-similarity of droplet breakup. Chemical Engineering Research and Design", 90, 1 85-192, 2012.

20. A.D.Vita and L.Allocca, "Experimental analysis and CFD simulation of GDI sprays," SAE Technical Paper 2003-01-0004, 2003.

21. H.P.Su, J.K.Hyung, K. S.Yyun and S.L.Chang,"Atomization and spray characteristics of bioethanol and bioethanol blended gasoline fuelinjected through a direct injection gasoline injector", International Journal of Heat and Fluid Flow, Vol.30, pp. 1183-1192, 2009a.

22. H.Hiroyasu, and M.Arai,; Structures of fuel sprays in diesel engines, SAE Technical Paper 900475 (1990).

23. G. Kumar and A. Kumar; Spray Behavior Comparison in Diesel Engine with Biodiesel as Fuel, Journal of Energy Technologies and Policy, Vol.3, No.4 (2013). 